\title{
Dietary cholesterol deprivation improves survival and reduces incidence of metastatic colon cancer in dimethylhydrazine-pretreated rats
}

\author{
J P CRUSE, M R LEWIN,** and C G CLARK \\ From the Department of Surgery, Faculty of Clinical Sciences, University College London, The Rayne \\ Institute, London
}

SUMMARY Cholesterol feeding of rats with colon cancer induced by dimethylhydrazine results in reduced survival and an increased incidence of metastatic colon cancer. As cholesterol may be implicated in the induction or maintenance of the metastatic process, an experiment was designed to determine whether rats with colon cancer would benefit from the removal of cholesterol from the diet. Female Wistar rats were treated with a colon cancer-inducing regimen of dimethylhydrazine ( $40 \mathrm{mg} / \mathrm{kg} /$ week for 10 weeks) while being fed on a standard cholesterol-containing rat pellet diet. After two rats had died spontaneously of histologically proven adenocarcinoma of the colon at 24 weeks, the remaining rats were randomly allocated in groups of 15 to one of three dietary regimens. Group $S$ continued to receive standard pellet diet, group $V$ were fed on Vivonex alone and group VC were fed Vivonex plus cholesterol $(10 \mathrm{mg} / 100 \mathrm{ml}$ Vivonex $)$. Each group was assessed for survival and incidence of histologically proven metastatic disease. There were no differences in either survival or incidence of metastases when groups S and VC were compared. In the cholesterol deprived group $\mathrm{V}$, however, there was a significant increase in survival compared with groups $S$ and VC $(p<0.02)$ and this was due to a significant reduction in the incidence of metastases $(p<0 \cdot 05)$. Cholesterol deprivation therefore benefits rats with established colon cancer induced by dimethylhydrazine by improving survival and reducing the incidence of metastases.

Patients with colorectal cancer generally die of metastases, ${ }^{1}$ and mortality from this disease is significantly correlated with dietary cholesterol consumption in industrialised countries. ${ }^{2}$ It has also been shown experimentally that cholesterol-fed rats have a greater mortality from chemically-induced metastatic colon cancer than do control rats fed on a cholesterol-free diet. ${ }^{3}$ Exposure to dietary cholesterol might therefore be implicated in the induction or maintenance of the metastatic process. As proliferating cancer cells usually lose the enzymatic capacity for endogenous cholesterol synthesis and thereby become dependent on exogenous sources of cholesterol, ${ }^{4}$ it has been postulated that the removal of cholesterol from the diet of the tumour-bearing host might inhibit the

* Address for correspondence: M R Lewin, as above, at 5 University Street, London WC1E 6JJ.

Received for publication 22 November 1981 metastatic process. ${ }^{5}$ This hypothesis was tested in a long term in vivo experiment, using the dimethylhydrazine-induced rat colon cancer model.

\section{Methods}

MATERIALS

The experimental methods and diets used have been described previously. ${ }^{3}$ Fifty outbred female Wistar rats (A Tuck) weighing 50-60 g were weaned onto a standard, cholesterol-containing pellet diet (Formula 41B, E Dixon and Sons). Thereafter, all animals received a 10 -week regimen of dimethylhydrazine dihydrochloride (Aldrich) at a dosage of $40 \mathrm{mg} / \mathrm{kg}$ body weight per week subcutaneously. Three rats died of toxicity during the induction period and were excluded from further consideration. During the induction period, and for the next 15 weeks, rats had free access to the pellet diet and fresh tap water. 
In the 24th week after the first dimethylhydrazine injection, two animals spontaneously died of histologically proven adenocarcinoma of the colon. In the 25 th week, the remaining 45 rats were randomly allocated in equal numbers to one of three diets. Group S ( $n=15)$ continued to receive diet 41B and water ad libitum, constituting a carcinogeninjected control group. Groups V and VC were both fed on Vivonex, a cholesterol-free liquid elemental diet. Group V $(n=15)$ were offered unmodified Vivonex $(100 \mathrm{ml} / \mathrm{rat} /$ day $)$ while group $\mathrm{VC}$ were offered the same quantity of Vivonex with added cholesterol $(10 \mathrm{mg} / 100 \mathrm{ml}$ Vivonex/rat/day), as previously described. ${ }^{3}$ The animals remained on these diets for the rest of their lifetimes. Animals were examined daily and weighed weekly, and either died spontaneously or were killed when fulfilling objective criteria. ${ }^{3}$ Complete necropsies, including histological examination of macroscopically abnormal tissue, were performed on all animals. The experimental design is shown in Fig. 1.

At necropsy, the cause of death was classified into one of the following histologically confirmed categories:

1 Death attributable to colon cancer, both primary and metastatic ( $\mathrm{P}$ and $\mathrm{M})$.

2 Death attributable only to primary (P) adenocarcinoma of the colon - for example, colonic obstruction, without evidence of metastases.

3 Death attributable only to metastatic (M) colon cancer (invasion of regional lymph nodes, omentum, liver, etc.).

4 Death attributable to 'other' $(\mathrm{O})$ causes - for example, pneumonia, fatal cancers of the ear canal, kidney, small intestine, etc.
Causes 2, 3, and 4 were mutually exclusive.

The experiment was evaluated by measuring three previously described indices ${ }^{3}$ - namely, the postrandomisation survival and the necropsy incidence of primary and metastatic colon cancer per group. Survival was assessed statistically by the logrank method of Peto et al, ${ }^{6}$ and included prospective stratification by cause of death. All other statistical comparisons were performed by using the one-tailed Fisher exact test. ${ }^{7}$

\section{Results}

The results were analysed when all the rats had died, approximately 33 weeks after dietary randomisation, and are summarised in Fig. 2 and Tables 1 and 2. At necropsy, every rat in the study, irrespective of when it died, had at least one histologically proven primary adenocarcinoma of the colon, indicating that colon tumours were probably already present at the time of randomisation. There was no significant difference between groups in respect of numbers of rats killed for humane reasons, nor in respect of numbers of rats dying of causes unrelated to colon cancer (Table 1).

Examination of the results (Fig. 2, Tables 1 and 2) shows that dimethylhydrazine-pretreated rats deprived of dietary cholesterol after randomisation onto the cholesterol-free diet (Vivonex, group V) show a significantly improved survival from death attributable to colon cancer $(\mathrm{P}+\mathrm{M})$ compared with the groups fed Vivonex plus cholesterol (group VC, p 0.02) or solid diet (group S, p 0.007). While there was no difference in survival between groups $\mathrm{V}$ and $\mathrm{VC}$ from all causes of death, group $\mathrm{V}$ did
WEEKS

EVENTS

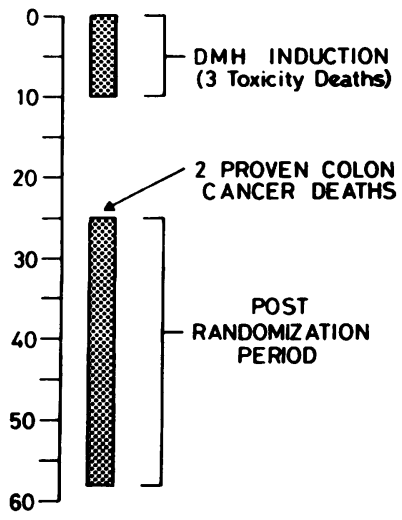

NUMBERS OF RATS

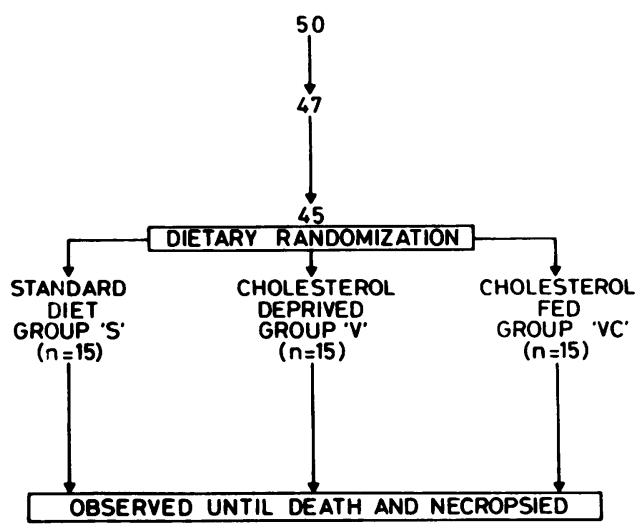

Fig. 1 Experimental design. 

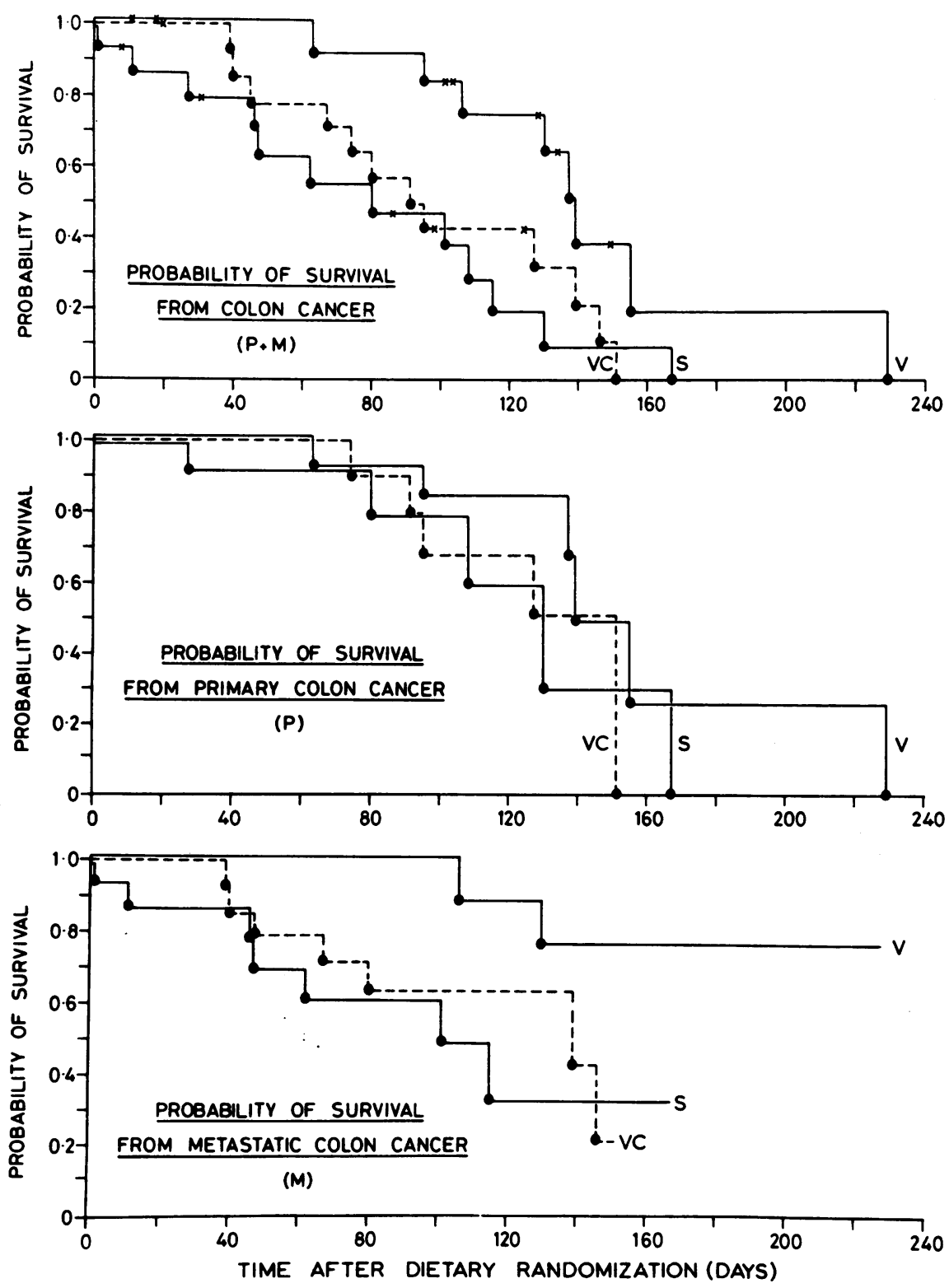

Fig. 2 Life tables of probability of survival from death attributable to (1) primary and metastatic colon cancer $(P+M)$, (2) primary colon cancer $(P)$, and (3) metastatic colon cancer $(M)$ as a function of time after dietary randomisation. $\bullet$ Death from relevant cancer, $x$ deaths from other causes

\begin{tabular}{|c|c|c|c|c|c|c|}
\hline \multirow[b]{2}{*}{$\begin{array}{l}\text { Cause of } \\
\text { death }\end{array}$} & \multirow[b]{2}{*}{$\begin{array}{l}\text { Dietary } \\
\text { group }\end{array}$} & \multicolumn{2}{|l|}{ Survival } & \multirow[b]{2}{*}{$\begin{array}{l}\text { Ratio } \\
\text { OIE }\end{array}$} & \multirow[b]{2}{*}{$x^{2}$} & \multirow[b]{2}{*}{$p$} \\
\hline & & $\begin{array}{l}\text { Observed } \\
\text { (O) }\end{array}$ & $\begin{array}{l}\text { Expected } \\
(E)\end{array}$ & & & \\
\hline $\mathbf{P}+\mathbf{M}$ & $\begin{array}{l}\text { S } \\
\text { VC } \\
\text { V }\end{array}$ & $\begin{array}{r}12 \\
12 \\
8\end{array}$ & $\begin{array}{r}7 \cdot 39 \\
9 \cdot 32 \\
15 \cdot 29\end{array}$ & $\begin{array}{l}1.62 \\
1.29 \\
0.52\end{array}$ & $7 \cdot 73$ & 0.02 \\
\hline $\mathbf{P}$ & $\begin{array}{l}\text { S } \\
\text { VC } \\
\text { V }\end{array}$ & $\begin{array}{l}5 \\
5 \\
6\end{array}$ & $\begin{array}{l}3.51 \\
4.07 \\
8.42\end{array}$ & $\begin{array}{l}1.43 \\
1.23 \\
0.71\end{array}$ & 1.69 & 0.43 \\
\hline $\mathbf{M}$ & $\begin{array}{l}\text { S } \\
\text { VC } \\
\text { V }\end{array}$ & $\begin{array}{l}7 \\
7 \\
2\end{array}$ & $\begin{array}{l}3 \cdot 88 \\
5 \cdot 25 \\
6 \cdot 87\end{array}$ & $\begin{array}{l}1.80 \\
1.33 \\
0.29\end{array}$ & $6 \cdot 73$ & 0.03 \\
\hline
\end{tabular}


Table 1 Post-randomisation survival and cause of death in dimethylhydrazine-pretreated rats

\begin{tabular}{|c|c|c|c|c|c|}
\hline \multirow[b]{2}{*}{$\begin{array}{l}\text { Dietary group } \\
(n=15)\end{array}$} & \multirow[b]{2}{*}{ Rat code } & \multirow[b]{2}{*}{$\begin{array}{l}\text { Survival } \\
\text { (days) }\end{array}$} & \multicolumn{3}{|l|}{ Cause of death } \\
\hline & & & $\begin{array}{l}\text { Primary } \\
\text { colon cancer }\end{array}$ & $\begin{array}{l}\text { Metastatic } \\
\text { colon cancer }\end{array}$ & $\begin{array}{l}\text { Other } \\
\text { causes }\end{array}$ \\
\hline \multicolumn{6}{|l|}{$\mathbf{S}$} \\
\hline \multirow[t]{15}{*}{ Standard diet } & S15 & 1 & & $\dagger$ & \\
\hline & S8 & 11 & & $\dagger$ & \\
\hline & S10 & 12 & & & $\dagger$ \\
\hline & S2 & $27^{*}$ & $\dagger$ & & \\
\hline & S13 & 31 & & & $\dagger$ \\
\hline & S3 & 46 & & $\dagger$ & \\
\hline & S9 & 47 & & $t$ & \\
\hline & S7 & 62 & & + & \\
\hline & S6 & 80 & $\dagger$ & & \\
\hline & S1 & 86 & & & $\dagger$ \\
\hline & S12 & 101 & & + & \\
\hline & S11 & 108 & $\dagger$ & & \\
\hline & S4 & 115 & & $t$ & \\
\hline & S5 & $130^{*}$ & $\dagger$ & & \\
\hline & S14 & $167^{*}$ & $\dagger$ & & \\
\hline \multicolumn{6}{|l|}{ VC } \\
\hline \multirow[t]{15}{*}{ Vivonex + cholesterol } & VC13 & 20 & & & + \\
\hline & VC15 & 39 & & $\dagger$ & \\
\hline & VC14 & 40 & & $\dagger$ & \\
\hline & VC6 & 46 & & $\dagger$ & \\
\hline & VC12 & 67 & & $\dagger$ & \\
\hline & $\mathrm{VC} 2$ & $74^{*}$ & $\dagger$ & & \\
\hline & VC7 & 80 & & $\dagger$ & \\
\hline & VC11 & $91^{*}$ & $\dagger$ & & \\
\hline & VC1 & $95^{*}$ & $\dagger$ & & \\
\hline & VC5 & 98 & & & $\dagger$ \\
\hline & VC9 & $124^{*}$ & & & $\dagger$ \\
\hline & VC3 & 127 & $t$ & & \\
\hline & VC10 & $139^{*}$ & & $\dagger$ & \\
\hline & VC8 & 146 & & $\dagger$ & \\
\hline & VC4 & 151 & + & & \\
\hline \multicolumn{6}{|l|}{ V } \\
\hline \multirow[t]{15}{*}{ Vivonex alone } & V2 & 11 & & & $\dagger$ \\
\hline & V5 & 18 & & & $\dagger$ \\
\hline & V11 & 63 & $\dagger$ & & \\
\hline & V15 & 95 & $\dagger$ & & \\
\hline & V14 & 101 & & & $\dagger$ \\
\hline & V3 & $103^{*}$ & & & $\dagger$ \\
\hline & V8 & 106 & $\cdot$ & $\dagger$ & \\
\hline & V7 & $128^{*}$ & & & $\dagger$ \\
\hline & V12 & 130 & & $\dagger$ & \\
\hline & V4 & 133 & & & $\dagger$ \\
\hline & V6 & 137 & $\dagger$ & & \\
\hline & V9 & 139 & $\dagger$ & & \\
\hline & V13 & $149^{*}$ & & & $\dagger$ \\
\hline & V10 & 155 & $\dagger$ & & \\
\hline & V1 & $229^{*}$ & $\dagger$ & & \\
\hline
\end{tabular}

* Killed for humane reasons. There were no significant differences in the numbers of rats killed between groups ( $\mathrm{p}$ values $>0.05$ ).

$\dagger$ Attribution of cause of death at necropsy.

show a significantly improved survival compared with the control group (S), irrespective of the cause of death (p 0.04). Figure 2 and Table 2 clearly demonstrate that the improved survival of group $\mathbf{V}$ is due to an improvement in survival from metastatic (M) rather than primary $(\mathrm{P})$ colon cancer, compared with groups VC (p 0.03) and S (p 0.01). This is confirmed by the necropsy findings (Table 1) which show no difference between groups in the incidence of primary colon cancer, but a significant reduction in the incidence of metastatic colon cancer in group V compared with groups VC $(p<0.05)$ and $S$ $(\mathrm{p}<0.05)$. Not only did significantly fewer rats in the cholesterol-deprived group (V) develop metastases, 
Table 2 P values of logrank analyses of survival by cause of death

\begin{tabular}{|c|c|c|c|c|}
\hline \multirow[b]{2}{*}{ Groups compared } & \multicolumn{4}{|l|}{ Cause of death } \\
\hline & $\begin{array}{l}\text { Primary and } \\
\text { metastatic } \\
\text { colon cancer }\end{array}$ & $\begin{array}{l}\text { Primary } \\
\text { colon cancer }\end{array}$ & $\begin{array}{l}\text { Metastatic } \\
\text { colon cancer }\end{array}$ & All causes \\
\hline $\begin{array}{l}\text { V vs VC } \\
\mathrm{V} v s \mathrm{~S} \\
\mathrm{VC} v s \mathrm{~S}\end{array}$ & $\begin{array}{l}0.02 \\
0.007 \\
\text { NS }\end{array}$ & $\begin{array}{l}\text { NS } \\
\text { NS } \\
\text { NS }\end{array}$ & $\begin{array}{l}0.03 \\
0.01 \\
\text { NS }\end{array}$ & $\begin{array}{l}\text { NS } \\
0 \cdot 04 \\
\text { NS }\end{array}$ \\
\hline
\end{tabular}

NS $=$ Statistically insignificant $(\mathrm{p}>0 \cdot 05)$.

Degrees of freedom $=1$ for all comparisons.

but (Fig. 2) those that did do so lived significantly longer than did the cholesterol-fed animals in either of the other two groups (VC and S) which subsequently died of metastatic disease (p 0.03). In contrast (Fig. 2, Tables 1 and 2), the cholesterol-fed group (VC) and the group fed solid diet (S) did not differ significantly in survival from any cause of death, nor in the incidence of metastatic colon cancer at necropsy. The findings indicate that only the cholesterol-deprived group (V) showed an improved survival and reduced incidence of metastases after dietary randomisation.

\section{Discussion}

There are no previous reports of the effects of reducing the cholesterol or fat content of the diets of dimethylhydrazine-pretreated animals. The mechanisms whereby cholesterol deprivation exerts a beneficial action are unknown, but the finding accords with data from other tumour models. For example, a cholesterol-free diet retarded tumour growth and/or prolonged the survival of mice bearing each of four different transplantable tumours (S180, Ehrlich carcinoma, CA 755, and Novikoff hepatoma), and chemical agents used to block cholesterol synthesis in vivo also retarded the growth of the above tumours. ${ }^{8}$ Similarly, cholesterol depletion of the host animal, either by a surgical operation (partial intestinal resection) or by feeding an Estrone-containing diet, limited the growth of Novikoff ascites tumours in vivo and prolonged the survival of the tumour-bearing rats. ${ }^{9}$ These data independently suggest that tumour growth may be retarded by limiting the amount of exogenous and endogenous cholesterol available to the tumourbearing host. Our observations corroborate the concept, and extend the findings to include inhibition of spontaneous metastases.

Critical evaluation of the present data suggests that the findings are unlikely to be attributable to confounding variables. For example, it could be postulated that the improved survival of group $\mathrm{V}$ animals is due to the effect of caloric restriction, ${ }^{10}$ but it has already been shown, in the same animal model, that the feeding of Vivonex with and without cholesterol produces no measurable differences in weight gain. ${ }^{3}$ Similarly, the possibility that the feeding of cholesterol to the control groups (VC and S) increased the number of cholesterol-related incidental deaths in these groups is not supported by the findings, as (see Table 1) these groups, in fact, had fewer incidental deaths than group V. Consequently, the results are attributable only to the experimental variable under study - namely, the cholesterol content of post-randomisation diet.

The present experiment provides no clues as to the mechanism whereby cholesterol deprivation exerts an antimetastatic action - that is, whether biochemical, hormonal, or immunological - nor as to whether the primary effect is on the host or on the tumour itself. The spread of cancer is, however, thought to be a multistage process ${ }^{11}$ and the removal of cholesterol from the diet or dimethylhydrazine-pretreated rats might conceivably reduce the probability of occurrence of any of these stages. While colon cancer cells can metastasise in the absence of dietary cholesterol (cf. group V in this experiment), the current data, and that of the previous experiment, ${ }^{3}$ are consistent with the interpretation that exposure to dietary cholesterol facilitates the metastatic process. Furthermore, the animal data suggest that cholesterol intake may be a determinant of the survival of the colon tumourbearing host. Epidemiological evidence now suggests the possibility of an analogous situation in man. ${ }^{2}$ It is therefore conceivable that patients with colorectal cancer might also benefit from dietary cholesterol deprivation after resection of their primary disease, as this may retard or inhibit the metastatic process.

We thank Eaton Laboratories for supplying and sharing the cost of Vivonex, Dr Richard Peto for his 
helpful criticism, Miss Pipa Skevington of the MRC Statistical Research and Services Unit for the survival analyses, and Diana Wilson for typing the manuscript. This work was carried out while JPC was a Rhodes Scholar.

\section{References}

1 Evans JT, Vana J, Aronoff BJ, Baker HW, Murphy GP. Management and survival of carcinoma of the colon. Results of a national survey by the American College of Surgeons. Ann Surg 1978; 188: 716-20.

2 Liu K, Stamler J, Moss D, Garside D, Persky V, Soltero I. Dietary cholesterol, fat and fibre, and colon-cancer mortality. An analysis of international data. Lancet 1979; 2: 782-5.

3 Cruse JP, Lewin MR, Ferulano GP, Clark CG. Cocarcinogenic effects of dietary cholesterol in experi- mental colon cancer. Nature 1978; 276: 822-5.

4 Chen HW, Kandutsch AA, Heiniger HJ. The role of cholesterol in malignancy. Prog Exp Tumor Res 1978; 22: 275-316.

5 Cruse JP, Lewin MR, Clark CG. Hypothesis: dietary cholesterol is cocarcinogenic for human colon cancer. Lancet 1979; 1: 752-5.

6 Peto R, Pike MC, Day HE et al. In: IARC monographs on the evaluation of the carcinogenic risk of chemicals to humans. Lyon: IARC, 1980: suppl 2; 311-426.

7 Siegel S. Nonparametric statistics for the behavioral sciences. New York: McGraw-Hill, 1956; 96-104.

8 Littman ML, Taguchi T, Mosbach EH. Effect of cholesterol-free diet and hypocholesteremic agents on growth of transplantable animal tumours. Cancer Chemother Rep 1966; 50: 25-45.

9 Schneider PD, Chan EK, Guzman IJ, Rucker RD, Varco RL, Buchwald H. Retarding Novikoff tumour growth by altering host rat cholesterol metabolism. Surgery 1980; 87: 409-16.

10 Tannenbaum A, Silverstone $H$. Nutrition in relation to cancer. Adv Cancer Res 1953; 1: 451-501.

11 Poste G, Fidler IJ. The pathogenesis of cancer metastasis. Nature 1980; 283: 139-46. 